\title{
Education Mediated by Technology: Strategy to Spread High School Learning in Piauí State, Brazil
}

\author{
Dalton Oswaldo Buccelli, Herbert Gonçalves Espuny, Jean Carlos Cavaleiro, \\ Pedro Luiz de Oliveira Costa Neto, Reinaldo de Araujo Lopes, \\ and Simone Maria Viana Romano \\ Paulista University - UNIP, Graduate Program in Production Engineering, \\ Dr. Bacelar St. 1212, São Paulo - SP, Brazil \\ \{dalton_buccelli, hgespuny, politeleia\}@uol.com.br, \\ ajean@ig.com.br, mestradoua@bol.com.br, \\ simone_viana@yahoo.com.br
}

\begin{abstract}
Brazil is a country of continental dimensions with huge need to provide basic education to its citizens, in particular those living in locations away from major centers. Among its 27 States, Piaui, located in the Northeastern region, has historically been considered one of the poorest of the Federation, but has now stood out for his efforts to resolve the educational problems. This work deals with a project of distance education based on lastgeneration technology, deployed in the State of Piauí in northeastern Brazil, in the year 2011. The difficulties of locomotion, truancy and the shortage of qualified teachers are some of the obstacles overcome by this pioneer project, that here is approached as a case study. Despite recent, this project has already got its first positive results.
\end{abstract}

Keywords: Distance learning, quality in education, developing countries.

\section{Introduction}

Located in the northeastern region of Brazil, the Piauí State has as its capital the city of Teresina, the most populous one. Is the third largest State in the region and the tenthin the country, with a land area of $251,529 \mathrm{~km}^{2}$, corresponding to $2.9 \%$ of the national territory. Borders five other Brazilian States: Maranhão, Ceará, Pernambuco, Bahia and Tocantins.According to itsEconomic and Social Research Center- CEPRO [1], the gross domestic product (GDP), which is the sum of all goods and services produced in the State, had in 2010 a total of about 11 billion US dollars, the highest value obtained by the State up to now.

According to the Brazilian Institute of Geography and Statistics - IBGE [2], the State of has a population of about 3 million people, 1 million living in the rural area and 2 million urban areas. In 2010, 829,143 peopleat school age between four and seventeen years old. Enrolled in high school, there were a total of 162,027 inhabitants, of whom 140,481 were students at public schools. 
The miss of high school regular offering occurs, mainly, due to the lack of qualified professionals in the poorest and of difficult access regions situated in the rural areasof the state. The geographical featuresand the insufficient means of transportation available to the residents of communities with low population density are obstacles to access schools that already offer high school.

These problems require, therefore, actions that enable the service to the student regardless of the type of access to his municipality or community, in respect to the Federal Constitution, item II of Art. 208, which guarantees as a duty of the State "the progressive universalization of free education" and, in Art. 211, paragraph 3"the States and the Federal District will act primarily in elementary and high schools" and 4 "in the organization of their education systems, the States and the municipalities shall define ways of cooperation, so as to ensure the universalization of compulsory education".

To meet this challenge, the Government of Piauí, through the Secretary of State for Education, performs the deployment of high school attendance mediated by technologies with the firm commitment to ensure decent social conditions for these young people, providing them with an education that allows the continuation of the studies, the construction and reconstruction of knowledge for the exercise of citizenship.

It is valid to add to these considerations the information given by the Brazilian Ministry of Education, thatlacks in the country 235,000teachers in high school and so $20 \%$ of youthsfrom 15 to 17 years old represent a repressed demand for this kind of educations.

\section{Distance Education}

Modern needs forced education to pass by transformations in its design in the last thirty years. These changes have brought new ideas, especially when it is focused on universalization of knowledge. A country of continental dimensions such as Brazil, and structural human and economic differences among regions must see in education the more consistent way to searchfor equality and social inclusion. Such education can be achieved through traditional or distance solutions, what historically led to a strong discussion.

However, given the evolution of distance education, today is not more relevant to discuss what is the best way, if distance or face-to-face, but rather provide the structure, models and resources used to achieve the common purpose of obtaining knowledge. As the focus of thispaper isdistance education (DE), and in particular by differences and regional needs that hampers access to education of the majority of the population, DE comes to fulfill the role of encouraging and giving access to a large portion of the Brazilian population that want to continue and improve his studies. Then, DE can be seen as a wayof universalization of knowledge in the country and in the world.

For [3], distance education is a technological system of two-way communication, which can be massive and replacing the personal interaction in the classroomamong teacher and students, as a means of teaching, for systematic action of several joint teaching resources and support for an organization and tutoring that provide the independent and flexible learning to students. 
For that DE arrived at a level of massive education, it was required the insertion of a lot of technology in this process. The evolution of communication technologies was responsible for the maturation of several models. According to [4], it is possible to see periods and features of models used in the course of time, thus existing five generations of DE activities, as shown in Figure 1.

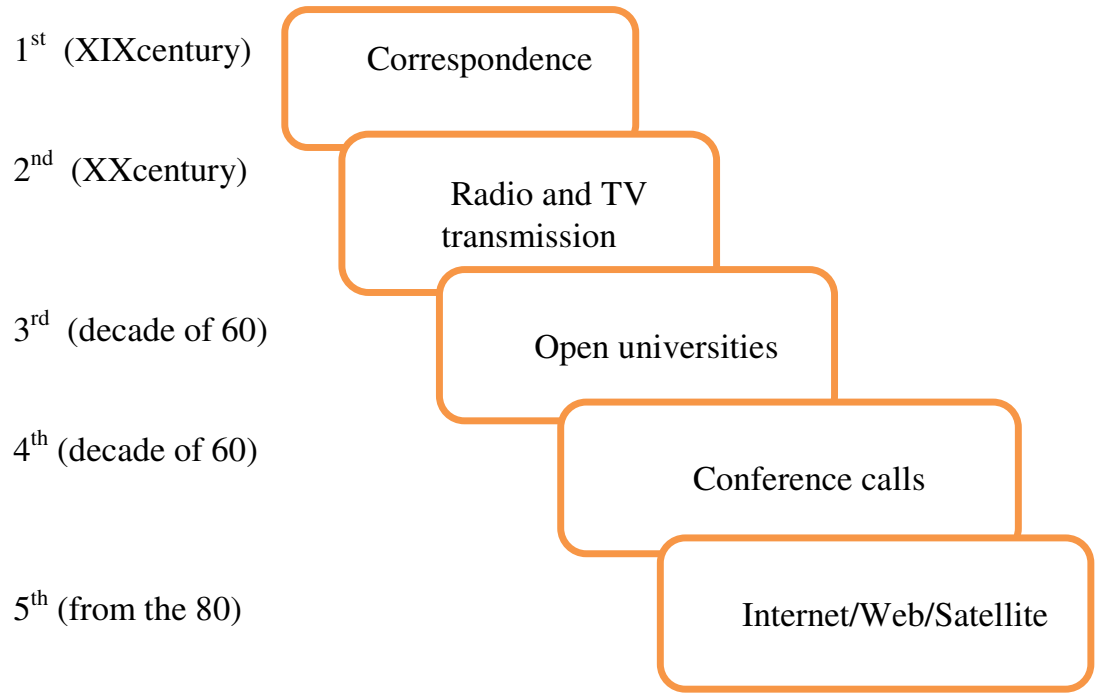

Fig. 1. Five generations of distance education Source: adapted from [4]

Table 1. Evolution of DE enrolments in graduate institutions in Brazil: 2009 - 2011

\begin{tabular}{|c|c|c|}
\hline Years & Institutions & Enrolments \\
\hline 2009 & 128 & 528.320 \\
\hline 2010 & 198 & 2.261.921 \\
\hline 2011 & 181 & 3.589.373 \\
\hline
\end{tabular}

The case study presented in this article is concerned with the $5^{\text {th }}$ generation of $\mathrm{DE}$, in whichthe evolution of technology provides the use of the Internet and computer networks enabling the convergence of text, audio and video into a single communication platform, integrating the advantages and earlier-generation technologies, and seeking to overcome the geographical barriers and communication. Features the use of the internet, virtual learning environments, multidirectional audio and video transmission, videoconferencing, etc. and all this without giving upthe 
advances provided by the previous generations, building a model with wide possibilities of learning.

This last generation, that makes an accumulation of experience of the last decades on DE, with itssafety and confidence in the model, has won followers around the world, including Brazil, where a State such Piauí is getting clear benefits with these solutions for the education problems. Table 1 shows the evolution of graduate DE enrolments in Brazil in recent years.

\section{Methodology}

In recent decades has occurred a considerable expansion in the use of qualitative methods in educational research and in studies related to business management. This is explained because many phenomena can only be understood in the contexts in which they occur and which they are part, and must be analyzed in an integrated perspective. For this integration to exist, the researcher must go into the scenery of the facts to observe the phenomenon being studied from the viewpoint of the people involved, collecting and analyzing data in different ways. The most important ways of acquiring data in qualitative research are documentary research and case study.

According to [6], the case study has become the preferred strategy when researchers seek to answer the questions "how" and "why" certain phenomena occur when there is little possibility of control over the events studied and when the focus of interest is on current phenomena, which can only be analyzed within some context of real life.To [7], the case study consists of a detailed investigation, with data collected over a period of time, of one or more organizations, or groups within organizations, to provide an analysis of the context and of the processes involved in the phenomenon under study. According to this author, the case study has been widely used in the field of organizational behaviour.

The qualitative research, more specifically the case study, encourages the engagement of the researcher with the daily life of organizations, providing a deep and integrated understanding of their realities. According to[6], when adopting an exploratory and descriptive approach, the researcher must be aware of their findings, even though starting from some theoretical scheme, keeping alert to new elements or dimensions that may arise in the course of thework.In this respect thecase study was planned to better understand how new technologies can assist in the process of universalization of education in one of the poorest States of the Brazilian Federation.

\section{$4 \quad$ Results and Discussions}

The project of implementing High School Attendance with Technological Mediation in the Piauí State was the administrative-pedagogical alternative to meetthe necessity of students concluding primary school in rural communities where there is no high school or the demand is higher than the supply.

The project offers high school with differentiated, innovative methodology, implementation of multimedia communication services network (data, voice and 
image) and autonomy to meet the 224 municipalities in 11 development areas of the State.

For that, it was necessary to establish a system of presential support poles,or points of presence, in Piaui State. [8] definespresential supportpole as an structure for the decentralized execution of the didatic-managerial functions of the course, consortium, net or system of Distance Education, in general organized with the participation of several institutions, and also with the support of municipal and state governments.

There were implemented 300 points of presence, whit the capacity of receiving up to 27,000 students, an average of 30 students per class, for high school and adult education, in three shifts, through a modern telecommunication platform. This platform to offer a modulatedserial instruction program through teleconferencing solution, including simultaneous access to broadband Internet and multidisciplinary team allocation to support the pedagogical coordination in the deployment and operation of the project. The technology used includes interactive digital TV over IP, through satellite in VSAT (Very Small Aperture Terminal) platform, as shown in Figure 2.

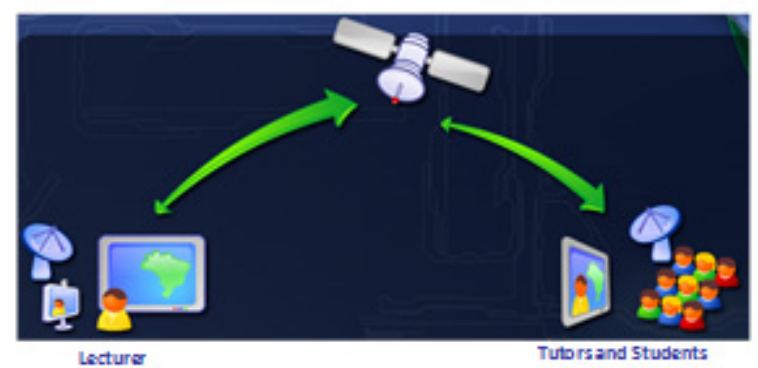

Fig. 2. Interactive digital TV over IP Source: [1]

The rural communities of the participating municipalities are provided with a network of multimedia communication services (data, voice and image) through a modern telecommunication platform including concurrent access to broadband Internet, with appropriate physical facilities.

The methodology is deployed through live classes, televised, uttered by a professor lecturer, from astudio located at TV Antares, in Teresina, allowing the student to attend these lectures at the school classroom in his community.

Under the guidance of a local teacher, a tutor called attendance teacher, present at each remote classroom, the student may interact with the professor lecturer, present in the broadcast studio, by positioning himself in front of a webcam, which will transmit his image, voice and question, resulting in an effective dialogue, in real time, ensuring the complete and interactive communication among the participants of the teaching and learning process.

This project responds to the dichotomy CHALLENGE = OPPORTUNITY, with the following characteristics:

- To overcome severe budget and infrastructure limitations; 
- To overcome the shortage of schools and teachers;

- The use of convergent technologies for optimization of the human and financial resources available;

- To promote the vocational qualification of young people and students from underprivileged regions.

The following are illustrative figures of the implementation of the project, provided by the authors.

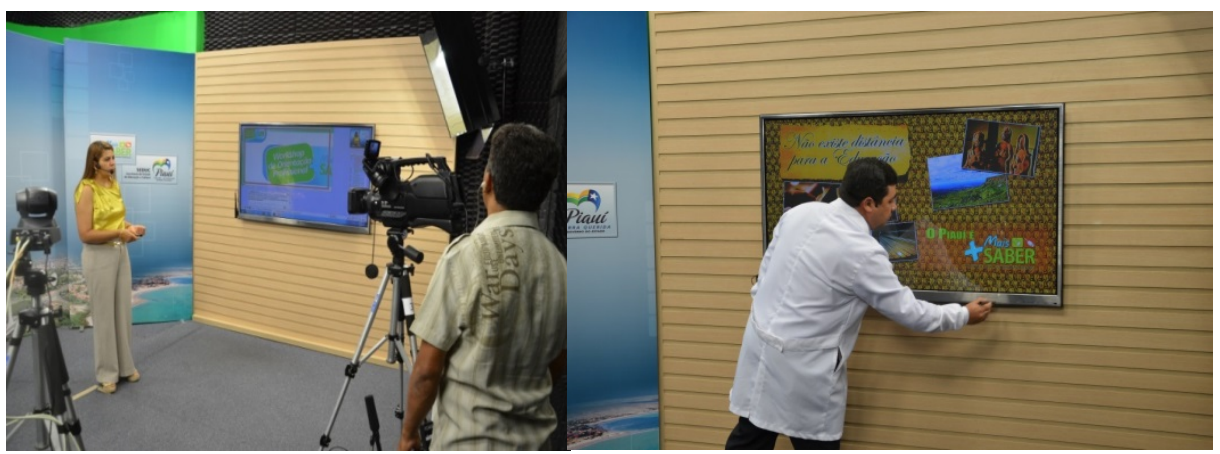

Fig. 3. Broadcast studio in Teresina
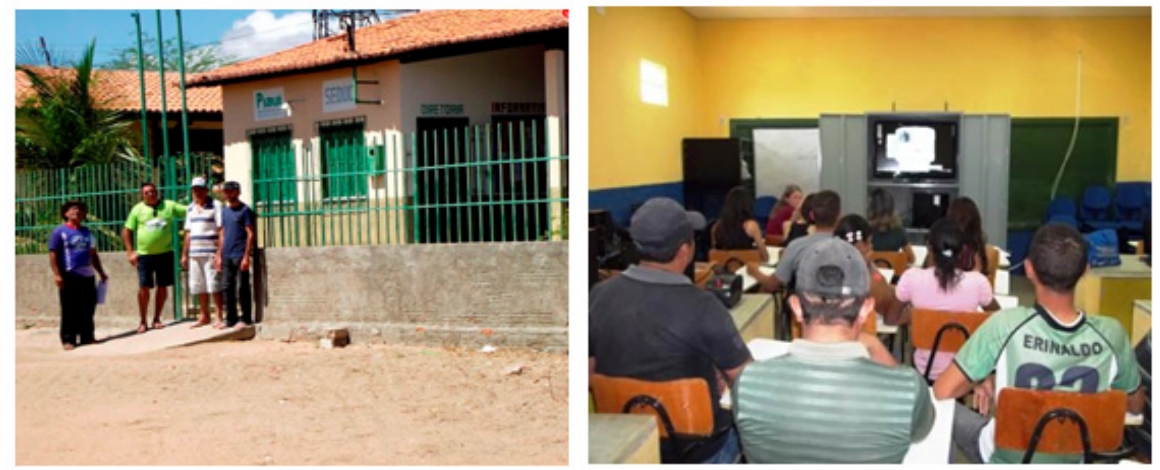

Fig. 4. Example of a school in Vila Nova do Piauí, a town about 350 miles away from the capital

The described education project has been implement at Piauí State and is running with its first group of students. So, results on effective learning are not yet available. However, it is expected that shall be reached advantage as good as the ones got in a similar project held inAmazonas State, shown in Table 2. 


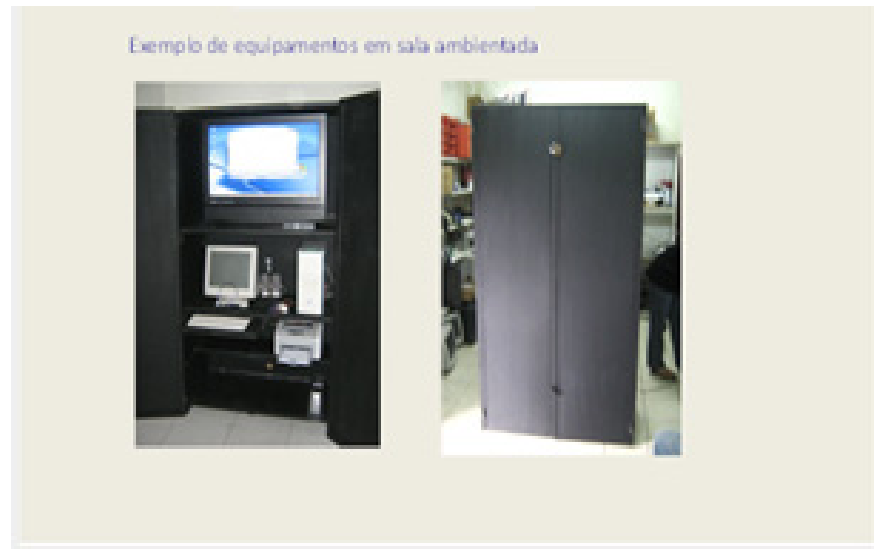

Fig. 5. Reception equipments at the remote classrooms

Table 2. Results of deproject in Amazonas State

\begin{tabular}{lcc}
\hline \multicolumn{1}{c}{ Item } & Before project & After project \\
\hline Approvals & $\mathbf{6 0 , 4 \%}$ & $\mathbf{7 7 , 5 \%}$ \\
Disapprovals & $\mathbf{1 2 , 8 \%}$ & $\mathbf{6 , 5 \%}$ \\
Truancy & $\mathbf{2 6 , 8 \%}$ & $\mathbf{1 6 , 0 \%}$ \\
\hline
\end{tabular}

Source: State Government of Amazonas

\section{Conclusions}

This article demonstrates the practical implementation, with real results, of a distance learning project using satellite transmission, covering remote accessed regions, local tutoring, resource optimization and search for excellence in pedagogical process using the best communicators as lecturer teachers, and interactivity with the remote rooms, as stated in the fifth generation of the distance learning processes.

The results prove the effectiveness of the used system in poor,spredand with disabilities regions, typical of countries with large territorial extension, as in the case of Brazil, particularly in the State of Piauí in the Northeast region. It is expected to have contributed for the dissemination of an experience of great value in education, illustrating its applicability in similar situations. 


\section{References}

1. CEPRO -Economic and Social Research Center ofPiauí, Piauí 's Regional Accounts Review (2010), http: / / www . cepro.pi.gov.br/201212 / CEPRO13 / download_fle6e3e34a.pdf (accessed: March 20, 2013)

2. IBGE - Brazilian Institute of Geography and Statistics, 2010 State of Piauí, http: / /www. ibge.gov . br/estadosat / perfil . php?=pi symbol (accessed: March 18, 2013)

3. Aretio, L.G.: Education for Today. National University of Distance. Education, Madrid (1994)

4. Moore, M., Kearsley, G.: Distance education: an integrated view. Thomson Learning, São Paulo (2007)

5. ABED - Brazilian Distance Education Association, Census EAD.br - Analytic Report of Distance Learning in Brazil. Pearson, São Paulo (2012)

6. Godoy, A.S.: Qualitative Research: fundamental types. Enterprises Management Review 35(3), 20-29 (1995)

7. Hartley, J.F.: Case studies inorganizational research. In: Cassell, C., Symon, G. (eds.) Qualitative Methods in Organizational Research: A Practical Guide. Sage, London (1995)

8. Mota, R.: Brazilian Open University. In: Litto, F.M., Formiga, M. (eds.) Distance Education - the State of the Art. Pearson - Prentice Hall, São Paulo (2009) 